\title{
Building Global Health Security Capacity: The Role for Implementation Science
}

Juliette Morgan, Erin D. Kennedy, Nicki Pesik, Frederick J. Angulo, Allen S. Craig,

Nancy W. Knight, and Rebecca E. Bunnell

$S_{\mathrm{A}^{\mathrm{n}}}^{\mathrm{n}}$ INCE The Launch of The Global Health Security Agenda (GHSA) in $2014,{ }^{1-3}$ many countries around the world have accelerated efforts to achieve compliance with the World Health Organization's (WHO) International Health Regulations (IHR 2005) to build their capacities to detect, assess, and report public health events. ${ }^{4}$ WHO approved a standardized Joint External Evaluation (JEE) tool in February 2016 that provides a framework for assessing a country's gaps and progress toward IHR 2005 implementation. ${ }^{5,6}$ By October 2018, more than 86 countries in 6 regions had completed a JEE. ${ }^{7}$ Based on JEE scores and recommended priority actions for improvement, multiple countries, in collaboration with technical partners such as the US Centers for Disease Control and Prevention (CDC), are actively working to build their capacities and strengthen core systems to prevent, detect, and respond to public health threats.

While notable progress has been achieved, many countries still fall short of IHR 2005 compliance. The need for more progress is further demonstrated by the 2018 Ebola outbreak in the Democratic Republic of the Congo and other recent infectious disease outbreaks around the world. ${ }^{4,8,9}$ A scientifically grounded evidence base, derived from formal evaluation of work during IHR 2005 implementation, could not only help maintain momentum for continued progress and stakeholder support, but could also provide global guidance on how to improve ongoing implementation activities.

As the WHO Collaborating Center for Implementation of IHR 2005 Core Capacities since 2009, CDC assists $\mathrm{WHO}$ and its member states in building and sustaining national IHR core capacities. As a scientific public health agency, CDC pledges to "base all public health decisions on the highest quality scientific data that are derived openly and objectively." 10

As governments throughout the world develop and implement their national action plans for health security to increase IHR 2005 capacities, it is necessary to increase the evidence base for IHR 2005 implementation to help inform plans, resource allocation priorities, and fiscal decisions for countries and donors. How does a government with limited resources discern which specific capacity-building approaches and interventions will enhance its ability to protect its population from threats that may not even be known today? What approaches are most effective and have the most impact in making progress on the IHR 2005 in specific technical areas such as laboratory, surveillance, workforce development, emergency response, and points of entry? What programmatic changes can be made to enhance the effectiveness and efficiency of current public health programs? What internal and external technical and fiscal contributions should a government prioritize to maximize

Juliette Morgan, MD, was, during the preparation of this publication, Associate Director for Science, Division of Global Health Protection, Center for Global Health; Erin D. Kennedy, DVM, MS, MPH, is Associate Director for Science, Epidemiology, Informatics, Surveillance, and Laboratory Branch, Division of Global Health Protection, Center for Global Health; Nicki Pesik, MD, is Associate Director for Infectious Disease Preparedness, National Center for Emerging and Zoonotic Infectious Diseases; Frederick J. Angulo, DVM, PhD, was Associate Director for Science, Division of Global Health Protection, Center for Global Health; Allen S. Craig, MD, is Deputy Director, National Center for Immunization and Respiratory Diseases; Nancy W. Knight, MD, is a captain in the US Public Health Service and Director, Division of Global Health Protection, Center for Global Health; and Rebecca E. Bunnell, $\mathrm{PhD}$, is Deputy Director for Science, Policy, and Communications, Division of Global Health Protection, Center for Global Health; all at the Centers for Disease Control and Prevention, Atlanta, GA. The findings and conclusions in this report are those of the authors and do not necessarily represent the official position of the Centers for Disease Control and Prevention. 
impact? Applying approaches from the field of implementation science can help inform the answers to these questions.

Implementation science is an evolving field that focuses on identifying effective implementation approaches, on translating research findings into routine and common practices, and on evaluating factors that influence the efficient adoption and implementation of public health interventions in real-life settings. ${ }^{1,12}$ Examples of implementation science areas of focus include acceptability, feasibility, costs, impact, and sustainability. ${ }^{13}$ The goals of implementation science are to understand how newly developed and scientifically proven health interventions and policies are adopted, integrated, and sustained, as well as to provide information to policymakers and implementers on how these interventions can be strengthened. Over the past decade, the US government's global health programs and partners have applied implementation science to evaluate and assess disease control programs, service delivery approaches, and program impact. ${ }^{14-18}$ The findings from these evaluations and studies helped major global programs employ more effective and efficient interventions. ${ }^{19-21}$

The articles included in this supplement describe lessons learned and present evidence from evaluations of efforts to build global health security capacity. By focusing current global health security programmatic and scientific work on implementation science, more useful evidence is generated that countries, stakeholders, collaborators, and donors need to more rapidly and efficiently build the sustainable health security capacities needed to meet the goals of IHR 2005 . $^{13,22}$ Development of a strategic scientific framework for global health security is necessary to provide the global public health community with an approach to studying the implementation of programs aimed at building capacity to prevent, detect, and respond to these public health threats. This framework should incorporate implementation science to assist in prioritizing investments by identifying the most effective interventions to strengthen global health security. Table 1 provides some examples of CDC's areas of interest for global health security implementation science through determining most effective interventions and measuring impact. The framework should also include a focus on basic epidemiologic research and surveillance to understand the causes of disease, as well as to characterize the burden and risk factors for these diseases; this is necessary to inform public health decision makers on which interventions should be developed, implemented, and evaluated to accelerate and optimize global health security.

Over the past 4 years, the world has seen significant investments in programs aimed at building surveillance, laboratory systems, and response capacity in regions hit hardest by public health threats. ${ }^{23-25}$ Now is a good time to use implementation science to learn as much as possible from these investments and share the evidence and lessons learned with all global health security partners to guide future efforts.

Table 1. Examples of CDC's Areas of Interest for Global Health Security Implementation Science

\begin{tabular}{|c|c|}
\hline $\begin{array}{l}\text { Determine the Most } \\
\text { Effective Implementation } \\
\text { Approaches }\end{array}$ & $\begin{array}{l}\text { - Assess best practices for program implementation. } \\
\text { - Evaluate current practices to identify feasibility, acceptability, and effectiveness } \\
\text { of the intervention. } \\
\text { - Determine optimal number of trained field epidemiologists and surveillance officers per } \\
\text { population or per subnational jurisdictional unit to appropriately detect, respond to, } \\
\text { and control public health threats. } \\
\text { - Examine the impact, costs, and cost-effectiveness of different models for the development } \\
\text { of an effective and efficient public health workforce. } \\
\text { - Examine health systems to quantify the impact of having several vertical public health } \\
\text { surveillance programs (eg, human immunodeficiency virus, tuberculosis, Expanded Program } \\
\text { on Immunization, malaria, and influenza) with an integrated surveillance system. } \\
\text { - Compare the impact, costs, and cost-effectiveness of different models of laboratory specimen } \\
\text { transport systems. } \\
\text { - Assess impact, cost, and cost-effectiveness of rapid diagnostic tests in field settings. } \\
\text { emergency management approaches, in humanitarian and other emergencies. }\end{array}$ \\
\hline Measure Impact & $\begin{array}{l}\text { - Measure the differences in outbreak response capacity before and after public health } \\
\text { investments in terms of days to detection, days to response, days to outbreak control, etc. } \\
\text { - Measure the impact of enhancements in public health surveillance, laboratory systems, and } \\
\text { enhanced emergency response in terms of number of outbreaks controlled, cases averted, time } \\
\text { lags from specimen detection to collection, etc. } \\
\text { - Measure the impact of an increase in trained public health workforce in terms of number } \\
\text { of outbreaks controlled, cases averted, time lags from specimen detection to collection, etc. } \\
\text { - Quantify the impact of key health interventions, such as childhood immunization, nutritional } \\
\text { supplementation, etc. } \\
\text { - Measure how programs for the prevention and control of noncommunicable diseases reduce } \\
\text { the burden of illness. }\end{array}$ \\
\hline
\end{tabular}


Partners from around the world working to strengthen global health security may benefit from incorporating implementation science into their capacity-building efforts, as it is critically needed to guide future investments for the implementation of IHR 2005. This can lead to an accelerated progress toward a world safe and secure from global health threats.

\section{ACKNOWLEDGMENTS}

We would like to thank Keisha Bohannon, Zara Ahmed, Ruth Cooke Gibbs, Jessica Gershick, Diane Brodalski, Cynthia Cassell, Joel Montgomery, Olga Henao, Michael Park, Michele Parsons, and Samuel L. Groseclose.

\section{REFERENCES}

1. Tappero JW, Cassell CH, Bunnell RE, et al.; Global Health Security Science Group. US Centers for Disease Control and Prevention and its partners' contributions to global health security. Emerg Infect Dis 2017;23(Suppl 1).

2. Katz R, Sorrell EM, Kornblet SA, Fischer JE. Global Health Security Agenda and the International Health Regulations: moving forward. Biosecur Bioterror 2014;12(5):231-238. doi: 10.1089/bsp.2014.0038.

3. US Centers for Disease Control and Prevention. Global Health-CDC and the Global Health Security Agenda. CDC website. Updated November 1, 2018. https://www.cdc.gov/ globalhealth/security/index.htm. Accessed November 8, 2018.

4. Gostin LO, Katz R. The International Health Regulations: the governing framework for global health security. Milbank Q 2016;94(2):264-313. doi: 10.1111/1468-0009.12186.

5. Forzley M. Global Health Security Agenda: Joint External Evaluation and legislation-A 1-year review. Health Secur 2017;15(3):312-319. doi: 10.1089/hs.2017.0013.

6. World Health Organization. Joint External Evaluation tool: International Health Regulations (2005). WHO website. 2016. http://apps.who.int/iris/handle/10665/204368. Accessed November 8, 2018.

7. World Health Organization. Strategic partnership for International Health Regulations (2005) and health security (SPH). 2018. https://extranet.who.int/sph/jee-dashboard. Accessed November 8, 2018.

8. Fitzmaurice AG, Mahar M, Moriarty LF, et al.; GHSA Implementation Group. Contributions of the US Centers for Disease Control and Prevention in implementing the Global Health Security Agenda in 17 partner countries. Emerg Infect Dis 2017;23(Suppl 1). doi: 10.3201/eid2313.170898.

9. Arie S. Ebola: WHO expresses "very serious concern" about Congo outbreak. BMJ 2018;363:k4430. doi: 10.1136/ bmj.k4430.

10. Centers for Disease Control and Prevention. Mission, role and pledge. CDC website. Last reviewed April 14, 2014. https:// www.cdc.gov/about/organization/mission.htm. Accessed November 8, 2018.

11. Padian NS, Holmes CB, McCoy SI, Lyerla R, Bouey PD, Goosby EP. Implementation science for the US President's
Emergency Plan for AIDS Relief (PEPFAR). J Acquir Immune Defic Syndr 2011;56(3):199-203. doi: 10.1097/ QAI.0b013e31820bb448.

12. Neta G, Brownson RC, Chambers DA. Opportunities for epidemiologists in implementation science: a primer. $\mathrm{Am} \mathrm{J}$ Epidemiol 2018;187(5):899-910. doi: 10.1093/aje/kwx323.

13. Peters $\mathrm{DH}$, Adam $\mathrm{T}$, Alonge $\mathrm{O}$, Agyepong IA, Tran N. Implementation research: what it is and how to do it. BMJ 2013;347:f6753. doi: 10.1136/bmj.f6753.

14. Pevzner ES, Vandebriel G, Lowrance DW, Gasana M, Finlay A. Evaluation of the rapid scale-up of collaborative TB/HIV activities in TB facilities in Rwanda, 2005-2009. BMC Public Health 2011;11:550. doi: 10.1186/14712458-11-550.

15. Naidoo N, Zuma N, Khosa NS, et al. Qualitative assessment of facilitators and barriers to HIV programme implementation by community health workers in Mopani district, South Africa. PLoS One 2018;13(8):e0203081. doi: 10.1371/journal.pone.0203081.

16. Long L, Brennan A, Fox MP, et al. Treatment outcomes and cost effectiveness of shifting management of stable ART patients to nurses in South Africa: an observational cohort. PLoS Med 2011;8(7):e1001055.

17. Plucinski MM, Chicuecue S, Macete E, et al. Evaluation of a universal coverage bed net distribution campaign in four districts in Sofala Province, Mozambique. Malar J 2014;13: 427. doi: 10.1186/1475-2875-13-427.

18. Holmes CB, Blandford JM, Sangrujee N, et al. PEPFAR's past and future efforts to cut costs, improve efficiency, and increase the impact of global HIV programs. Health Aff (Millwood) 2012;31(7):1553-1560. doi: 10.1377/hlthaff. 2012.0562.

19. Njeuhmeli E, Stegman P, Kripke K, et al. Modeling costs and impacts of introducing early infant male circumcision for long-term sustainability of the voluntary medical male circumcision program. PLoS One 2016;11(7):e0159167. doi: 10.1371/journal.pone.0159167.

20. McCreesh N, Andrianakis I, Nsubuga RN, et al. Universal test, treat, and keep: improving ART retention is key in costeffective HIV control in Uganda. BMC Infect Dis 2017; 17(1):322. doi: 10.1186/s12879-017-2420-y.

21. McNairy ML, Bashi JB, Chung H, et al. Task-sharing with nurses to enhance access to HIV treatment in Côte d'Ivoire. Trop Med Int Health 2017;22(4):431-441. doi: 10.1111/ tmi.12839.

22. Galea S. An argument for a consequentialist epidemiology. Am J Epidemiol 2013;178(8):1185-1191. doi: 10.1093/aje/ kwt172.

23. Bell BP, Damon IK, Jernigan DB, et al. Overview, control strategies, and lessons learned in the CDC response to the 2014-2016 Ebola epidemic. MMWR Suppl 2016;65(3):4-11. doi: $10.15585 / \mathrm{mmwr.su6503a2}$.

24. Brooks JC, Pinto M, Gill A, et al. Incident management systems and building emergency management capacity during the 2014-2016 Ebola epidemic-Liberia, Sierra Leone, and Guinea. MMWR Suppl 2016;65(3):28-34. doi: 10.15585/mmwr.su6503a5.

25. Marston BJ, Dokubo EK, van Steelandt A, et al. Ebola response impact on public health programs, West Africa, 20142017. Emerg Infect Dis 2017;23(Suppl 1). doi: 10.3201/ eid2313.170727. 